\title{
ACCESS TO JUSTICE ONLINE: Are Canadian Court Websites AcCessible FOR USERS WITH VISUAL IMPAIRMENTS?
}

\author{
CODY REI-ANDERSON, , GRAHAM REYNOLDS, ${ }^{* *}$ \\ JAYDE WOOD, ${ }^{* * *}$ AND NATASHA WOOD ${ }^{* * * *}$
}

\begin{abstract}
Steps taken to make legal information available online have resulted in access to justice benefits for many. However, these benefits may not extend to everyone equally. As scholars have cautioned, the adoption of new technologies that purport to improve access to justice may perpetuate the exclusion of vulnerable and marginalized individuals and groups from the justice system. This article applies this insight to legal information made available online by Canadian court websites and CanLII.
\end{abstract}

It does so through a two-part study. First, we used an automated testing tool to determine whether the websites noted above comply with accessibility standards. Second, after having secured research ethics approval, we worked with Access \& Diversity at the University of British Columbia to recruit persons with visual impairments; these participants evaluated the same websites and provided feedback. Our results showed that while largely accessible, the tested websites fall short of best practices, presenting challenges to users with visual impairments. We recommend that Canadian courts correct the deficiencies identified by our study, that other online legal resources be tested for accessibility issues, and that future research focus on the extent to which online legal resources are accessible to other vulnerable or marginalized individuals or groups. Implementing these recommendations will ensure that the access to justice benefits of online legal information are extended to everyone.

\section{TABLE OF CONTENTS}

I. INTRODUCTION . . . . . . . . . . . . . . . . . . . . . . . . . . . . . . . . . . 648

II. ONLINE LEGAL INFORMATION AND ACCESS TO JUSTICE . . . . . . . . . . . . 649

A. What Is Access to Justice? . . . . . . . . . . . . . . . . . . 649

B. Access to Justice And Technology . . . . . . . . . . . . 651

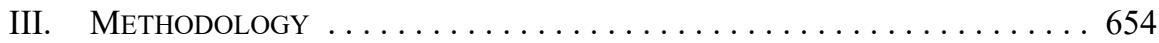

A. The Websites Tested: Canadian Courts And CanLiI . . . . 654

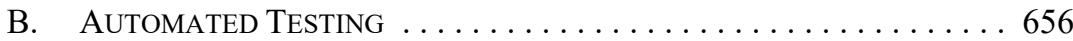

C. User Testing . . . . . . . . . . . . . . . . . . . . . . . 659

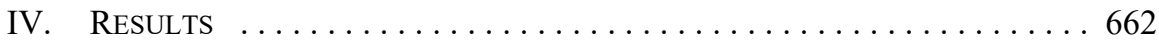

A. Automated Test Results $\ldots \ldots \ldots \ldots \ldots \ldots 6 . \ldots \ldots 6 . \ldots \ldots 6$

B. User Test Results . . . . . . . . . . . . . . . . . . . . . 667

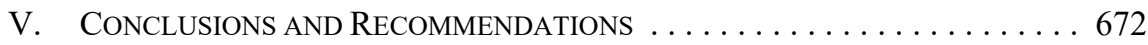

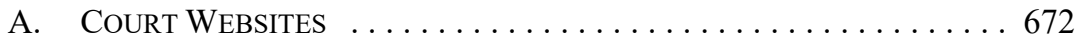

** $\quad$ BA\&Sc (McGill University); JD, LLM Candidate (University of British Columbia).

BA (University of Manitoba), LLB (Dalhousie University), BCL, MPhil, DPhil (Oxford University); Assistant Professor, Peter A. Allard School of Law at the University of British Columbia.

*** $\quad$ BSc, MSc, JD (University of British Columbia); Associate, Oyen Wiggs Green \& Mutala LLP.

**** BA (Hons), MA (University of Victoria); JD (University of British Columbia); Associate, Guild Yule LLP. The authors wish to acknowledge the Social Sciences and Humanities Research Council for funding Towards Cyberjustice: Rethinking Processual Law, an MCRI headed by Karim Benyekhlef at the Université de Montréal, of which this article forms a part. We would also like to thank JonasSébastien Beaudry as well as several anonymous peer reviewers for their helpful comments. Any errors or omissions are solely the responsibility of the authors. 
B. Benefits of Pairing Automated And User Testing . . . . . . 673

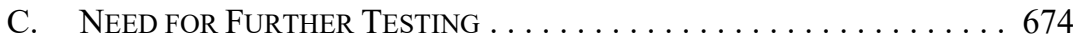

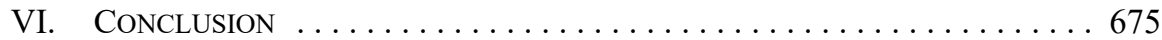

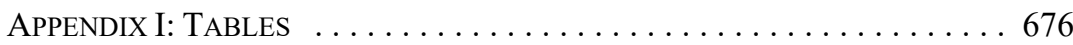

APPENDIX II: USER TESTING SAMPLE SURVEY . . . . . . . . . . . . . . . 679

\section{INTRODUCTION}

In recent years, a wide range of entities - from private corporations to courts - have taken steps to make legal information available online. Individuals with access to Internetenabled devices can read case law, ${ }^{1}$ watch webcasts of court proceedings, ${ }^{2}$ examine facta, ${ }^{3}$ and locate basic court information such as daily schedules and the location of courthouses. ${ }^{4}$ Much of this information is freely available.

The delivery of legal information to the public over the Internet has been, in many respects, a boon to access to justice. In addition to facilitating access to courts, ${ }^{5}$ the making available of legal information online has helped to make the process of law as well as laws themselves both more easily accessible to the public and more comprehensible. ${ }^{6}$

However, it is not necessarily the case that everyone benefits equally from efforts taken to make legal information available online. As a number of scholars have cautioned, the adoption and use of new technologies that purport to improve access to justice (for instance, the use of the Internet to make legal information more broadly available) may perpetuate the exclusion of already vulnerable and marginalized individuals and groups from the justice system. This is particularly the case if in-person access to legal information is reduced or curtailed as a result of the move to increase online access to legal information. ${ }^{7}$

This article applies these insights in the context of legal information made available online by Canadian court websites and the Canadian Legal Information Institute (CanLII). In particular, it considers the extent to which specific Canadian court websites and CanLII are accessible for persons who are blind or have visual impairments. ${ }^{8}$ In order to determine this, we constructed a two-part study. First, we used an automated testing methodology to

See e.g. Canadian Legal Information Institute, online: $<$ https://www.canlii.org/en/>.

See e.g. Supreme Court of Canada, "Archived Webcasts," online: <www.scc-csc.ca/case-dossier /info/webcasts-webdiffusions-eng.aspx>.

3 See e.g. Supreme Court of Canada, "SCC Case Information," online: <www.scc-csc.ca/case-dossier/ info/search-recherche-eng.aspx $>$.

$4 \quad$ See e.g. Supreme Court of British Columbia, "Court Locations \& Contacts," online: <www.courts.gov. bc.ca/supreme court/court locations and contacts.aspx $>$.

5 For instance, court websites function as a primary, authoritative source for information on court locations, opening hours, and procedures - essential information for those attempting to access the justice system.

6 See Yaniv Roznai \& Nadiv Mordechay, "Access to Justice 2.0: Access to Legislation and Beyond" (2015) 3:3 Theory \& Practice Legislation 333; Cecilia Magnusson Sjöberg, "Legal Information Supply and the Digital Divide" (2007) 50 Scand Stud L 393 at 395.

Patricia Hughes, for instance, suggests that "[f]or people with low literacy, the failure to provide inperson assistance throughout the legal process is a denial of access to justice": Patricia Hughes, "Advancing Access to Justice Through Generic Solutions: The Risk of Perpetuating Exclusion" (2013) 31:1 Windsor YB Access Just 1 at 18 [Hughes, "Generic Solutions"].

8 As described in more detail below, our study examined the websites for the Supreme Court of Canada, the Federal Courts, and courts in Ontario and British Columbia. For a comprehensive list, see Part III.A, below. 
determine whether and the extent to which the websites noted above violate established accessibility principles. Second, after having secured research ethics approval, we worked with Access \& Diversity at the University of British Columbia (UBC) to recruit persons with visual impairments. These participants engaged in task-based and holistic user testing of the same websites and provided feedback on their experiences.

Our study found that the websites we tested are largely accessible for persons who are blind or who have visual impairments, but fall short of best practices in a number of ways. The automated testing we conducted identified issues on these websites that could limit the extent to which users who are blind or who have visual impairments are able to access and use the legal information made available online. The issues found meant that all of the websites surveyed fail to fully comply with the Web Content Accessibility Guidelines 2.0 (WCAG), ${ }^{9}$ a comprehensive standard for making web content accessible for persons with disabilities. User comments highlighted some of the same accessibility issues that were identified through automated testing, as well as others that automated testing could not identify. They also provided a more nuanced understanding of precisely how these users were impacted by the accessibility issues present in these websites.

In order to ensure that online legal information is accessible for users who are blind or who have visual impairments, we recommend that Canadian courts take steps to correct some of the deficiencies identified in this study, as well as engage in further testing (both automated and user) in order to pinpoint accessibility issues that need to be resolved. As well, given the important access to justice benefits that flow from the making available, online, of legal information, we also recommend further testing in order to determine the extent to which other types of online legal information (including self-help legal resources aimed at the general public as well as internal law firm documents) are accessible for users with disabilities as well as users who are members of other vulnerable or marginalized groups.

\section{ONLINE LEgAL INFORMATION AND ACCESS TO JUSTICE}

\section{A. What Is ACCESS To Justice?}

In 2005, Roderick Macdonald wrote that "[s]ince the slogan 'access to justice' burst upon the legal scene forty years ago there has been little agreement about what it means." ${ }^{10}$ In the

World Wide Web Consortium (W3C), "Web Content Accessibility Guidelines (WCAG) 2.0" (11 December 2008), online: <https://www.w3.org/TR/WCAG20/> [W3C, "WCAG 2.0"]. Government guidelines at the federal and provincial levels mandate compliance with these guidelines for government websites. In addition, governments may have the responsibility to make web content accessible under the Charter's equality guarantee, as well as international instruments. See Canada (Attorney General) $v$ Jodhan, 2012 FCA 161, [2014] 1 FCR 185 [Jodhan] (holding that "the failure [of the Treasury Board] to ensure equal access by Ms. Jodhan and by the visually impaired to departmental websites and online services violated her rights under subsection 15(1) [of the Charter]" at para 161); Government of Ontario, "How to Make Websites Accessible," online: <www.ontario.ca/page/how-make-websitesaccessible>.

10 Roderick A Macdonald, “Access to Justice in Canada Today: Scope, Scale and Ambitions” in Julia Bass, WA Bogart \& Frederick H Zemans, eds, Access to Justice for a New Century: The Way Forward (Toronto: Law Society of Upper Canada, 2005) 19 at 19. Trevor Farrow, for instance, considers access to justice through a study of views of the general public, identifying in the responses "two underlying themes .... a access to the kind of life — and the kinds of communities in which — people would like to live" and civic engagement, that the "voice of the public" should be a "central feature of all access-to- 
absence of an agreed-upon conception of access to justice, Macdonald's identification of five "waves" of access to justice thinking has been influential in both Canada and abroad. ${ }^{11}$ Viewing access to justice in terms of "waves" of historical development helps to recognize the concept's diverse facets, which in turn helps to identify relevant access to justice goals. ${ }^{12}$ Each of Macdonald's waves correspond roughly to decades:

1. Access to lawyers and courts (1960-1970), for which "the concept [of access to justice] meant little more than access to courts and to lawyers"; ${ }^{3}$

2. Institutional redesign (1970-1980), which concerned itself with "[i]ssues such as the actual performance of courts, their procedures, and their organization"; ${ }^{4}$

3. Demystification of law (1980-1990), wherein "[m]uch effort was devoted to promoting ADR [alternative dispute resolution] and other mechanisms for 'dejudicializing' civil justice" and "the attention of scholars and activists moved towards programmes of public legal information and education"; 15

4. Preventative law (1990-2000), in which "[a]n entirely different view of ADR was proposed in which these processes were also viewed as vehicles to help citizens avoid conflicts, or deal with them before they became crystallized as legal problems"; ${ }^{16}$ and

5. Proactive access to justice (2000 onwards), which recognized that "[i]n a liberal democracy, true access to justice requires that all people should have an equal right to participate in every institution where law is debated, created, found, organized, administered, interpreted and applied." $" 17$

justice reform efforts": Trevor CW Farrow, "What Is Access to Justice?" (2014) 51:3 Osgoode Hall LJ 957 at 983 . Jennifer Leitch, on the other hand, focuses on access to justice as democratic participation, and on client participation in legal processes as furthering participatory democracy: see Jennifer A Leitch, "Having a Say: 'Access to Justice' as Democratic Participation" (2015) 4:1 UCLJLJ 76.

11 The idea of "waves" of access to justice originates with Cappelletti \& Garth and the Florence Access to Justice Project: Mauro Cappelletti \& Bryant Garth, eds, Access to Justice, Vol I: A World Survey (Milan: Giuffrè, 1978). Macdonald references their work and adds two further "waves" corresponding to the two decades that had passed since the publication of the Cappalletti \& Garth piece. For articles which have cited Macdonald's approach, see Micah B Rankin, “Access to Justice and the Institutional Limits of Independent Courts” (2012) 30:1 Windsor YB Access Just 101 at 105 (citing Macdonald as rebutting formalism in the definition of access to justice, and connecting access to justice concerns to judicial independence); Patricia Hughes, "Law Commissions and Access to Justice: What Justice Should We Be Talking About?" (2008) 46:4 Osgoode Hall LJ 773 [Hughes, "Law Commissions"] (describing Macdonald's theory as going "much further afield" than Cappalletti \& Garth's by going beyond the legal system (at 780, n 22)); Mary Jane Mossman, Karen Schucher \& Claudia Schmeing, "Comparing and Understanding Legal Aid Priorities: A Paper Prepared for Legal Aid Ontario" (2010) 29 Windsor Rev Legal Soc Issues 149 (looking at Ontario's legal aid regime and arguing for a broader and more socially inclusive concept of access to justice based on Macdonald and Cappalletti's "waves" of access to justice); Jane Bailey, Jacquelyn Burkell \& Graham Reynolds, “Access to Justice for All: Towards an 'Expansive Vision' of Justice and Technology” (2013) 31:2 Windsor YB Access Just 181.

Macdonald, supra note 10 at 24.

Ibid at 20 .

Ibid.

Ibid at 22 .

Ibid.

Ibid at 23. But see William E Conklin, "Whither Justice? The Common Problematic of Five Models of "Access to Justice"” (2001) 19 Windsor YB Access Just 297. Conklin, in contrast, concludes that efforts towards access to justice have been misguided insofar as they are merely "an access to the lawyer's language which conceals the bodily meanings which the non-knower brings into her/his own signs" (Conklin, ibid at 316). In Conklin's critique of the access to justice movement, mere access to the 
This article focuses on the question of whether and the extent to which legal information made available online by specific Canadian courts and CanLII is accessible to persons who are blind or who have visual impairments. For this purpose, Macdonald's fifth wave which acknowledges the importance of ensuring that members of vulnerable and marginalized groups have equal rights of participation in all sites where law is found or made $^{18}$ — is of prime importance. As Justice McEwan wrote in Vilardell v. Dunham, "[t]he inherent dignity of the human person cannot be respected in a regime of exclusion and institutional inequality; nor can commitment to social justice and equality, nor can accommodation of different beliefs and respect for cultural and group identity." 19 With that in mind, digital technologies - increasingly ubiquitous in society and employed in the justice sector - should be subject to scrutiny to ensure that any benefits that they provide are extended to all individuals.

\section{B. ACCESS TO JUSTICE ANd TeChNOLOGY}

The adoption of technologies and practices in the justice sector that take advantage of the Internet and related technologies has had a number of purported access to justice benefits. ${ }^{20}$ For instance, commentators have suggested that free or affordable legal software and online self-help tools directed at the public can help individuals avoid or resolve legal problems

institutions of law would be insufficient, because the experiential meanings that exist beyond such institutions would continue to be obscured: see Faisal Bhabha, "Institutionalizing Access-to-Justice: Judicial, Legislative and Grassroots Dimensions" (2007) 33:1 Queen's LJ 139 at 144-45. While Macdonald's prescription for a proactive access to justice strategy would also go beyond access to institutions, "establishing partnerships with health and social services agencies" would not seem on its face to address Conklin's concern: Macdonald, supra note 10 at 23. See also Hughes, "Law Commissions," supra note 11 at 783 (considering Conklin's critique).

18 Macdonald identifies "five main dimensions" which correlate with exclusion from access to justice: economic disadvantage, socio-demographic factors, stigmatization, disabilities and health problems, and psychological factors: Macdonald, ibid at 29-31.

192012 BCSC 748, 260 CRR (2d) 1 at para 405, rev'd 2013 BCCA 65, 359 DLR (4th) 524, rev'd 2014 SCC 59, [2014] 3 SCR 31. While the Supreme Court of Canada ultimately overturned the decision, this quote remains a powerful statement of the importance of access to justice and its connection to fundamental values.

20

See, for instance, the Towards Cyberjustice project, of which this article forms a part: Cyberjustice Laboratory, "Towards Cyberjustice," online: <www.cyberjustice.ca/en/projets/vers-la-cyberjustice/>. There have also been a number of recent initiatives aimed at other problems in access to justice. For articles discussing simplified court procedures, see e.g. Jonathan Silver \& Trevor CW Farrow, "Canadian Civil Justice: Relief in Small and Simple Matters in an Age of Efficiency" (2015) 8:4 Erasmus L Rev 232 (considering simplified civil court procedures as a way of promoting access to justice); Lesly Joseph, "Rule 76 - Costs, Benefits and Implications for Access to Justice" (2008) 34:1 Adv Q 88 (discussing simplified court procedures in Ontario civil litigation rules through the lens of access to justice). For articles discussing the regulation of legal services provided by non-lawyers, see e.g. Suzanne Bouclin, "Regulated Out of Existence: A Case Study of Ottawa's Ticket Defence Program" (2014) $11 \mathrm{JL} \&$ Equality 35 (discussing an Ottawa area access to justice program ended by paralegal regulation); Jennifer Bond, David Wiseman \& Emily Bates, "The Cost of Uncertainty: Navigating the Boundary Between Legal Information and Legal Services in the Access to Justice Sector" (2016) 25 JL \& Soc Pol'y 1 (considering legal support services rendered by non-lawyers \& outside regulated legal services [so excluding, for example, paralegals] to promote access to justice). For other approaches, see e.g. Hughes, "Law Commissions," supra note 11 (considering law commissions' mandates to promote access to justice, and advocating for a broader conception of access to justice in these mandates); Frederick Zemans \& James Stribopoulos, "Peer Review in Canada: Results From a Promising Experiment" (2008) 46:4 Osgoode Hall LJ 697 (proposing peer review as method to measure quality of legal aid services); Andrew Pilliar, "Law and the Business of Justice: Access to Justice and the Profession/Business Divide" (2014) 11 JL \& Equality 5 (arguing that revisiting the profession-business divide in provision of legal services could improve access to justice). 
without incurring significant costs; ${ }^{21}$ the use of computer technology in the courtroom has been cited as a way to cut down on the length of trials, decreasing the cost of legal representation; ${ }^{22}$ and online streaming video of court proceedings has made it possible for members of the public to watch court proceedings that they cannot physically attend. ${ }^{23}$

This article focuses on one such practice that has been made possible by the development and popularization of the Internet and related technologies: the making available, online, of legal information. ${ }^{24}$ The access to justice benefits of online legal information are numerous. For example, access to courts is aided by the provision of information regarding court hours, locations, and dockets. As well, legal information being made readily available to the public over the Internet allows individuals to more easily inform themselves of their legal status and obligations, which could help to prevent legal issues before they arise, as well as help individuals to decide whether to move ahead with a lawsuit. ${ }^{25}$ Finally, there is the basic and crucial purpose served by the making available, online, of legal information, namely ensuring the widespread availability of law (including case law and legislation), which is both important to access to justice and fundamental to the rule of law. ${ }^{26}$

These benefits - which engage at least three of the five waves Macdonald identifies (access to lawyers and courts, demystification of law, and preventative law) - may be particularly advantageous for persons in remote communities or with mobility issues, who might face challenges in accessing legal information in physical formats at libraries or other locations. $^{27}$

As a number of commentators have emphasized, however, it cannot be assumed that the benefits of technological solutions to access to justice problems extend to all individuals equally. ${ }^{28}$ As noted in a co-author's previous paper, "the relationship between access to

See e.g. Ronald W Staudt, "All the Wild Possibilities: Technology That Attacks Barriers to Access to Justice" (2009) 42:4 Loy LA L Rev 1117; Trish O'Sullivan, "Developing an Online Dispute Resolution Scheme for New Zealand Consumers Who Shop Online - Are Automated Negotiation Tools the Key to Improving Access to Justice?" (2016) 24:1 Intl JL \& IT 22; Suzanne Bouclin, Jena McGill \& Amy Salyzyn, "Mobile and Web-Based Legal Apps: Opportunities, Risks and Information Gaps" CJLT [forthcoming], online: $<$ papers.ssrn.com/sol3/papers.cfm?abstract id=2960207>.

22 See Hugh Calkins, "The Access to Justice Technology Bill of Rights" (2004) 19 Me Bar J 202 (an early perspective considering the potential of technology to improve access to justice - but noting that e-filing requirements could cause accessibility problems, for example, for prison inmates with no computer access); Luigi Benetton, "E-Trials in Canada," CBA National Magazine (September 2011), online: $<$ https://web.archive.org/web/20150923081102/http://www.cba.org/CBA/practicelink/leadership technology/etrials.aspx $>$ (stating that "[f]or litigants, the benefits of e-trials are clear as it boils down to a question of access to justice" and citing Graham Underwood and Jonathan Penner for the proposition that "[p]roperly applied, technology should cut trial times from a quarter to a half"). James E Cabral et al, "Using Technology to Enhance Access to Justice" (2012) 26:1 Harv JL \& Tech 241 at 248 (addressing court and legal aid websites as access to justice resources; noting at 262-63 that online information can present issues for persons with disabilities).

24 For other papers that address this topic, see e.g. ibid; Anna L Endter, "Authentication of Online State Primary Legal Resources as a Social Justice Issue: The Uniform Electronic Legal Material Act and How It Can Benefit Pro Se Litigants" (2012) 31 Leg Ref Serv Q 293 (discussing the importance, as an issue of social justice, of providing vulnerable users with "access to authentic and trustworthy electronic versions of the laws that govern them" at 293); Mark Lloyd, "The Digital Divide and Equal Access to Justice" (2002) 24:4 Hastings Comm \& Ent LJ 505 at 529-30.

See Bailey, Burkell \& Reynolds, supra note 11 at 188 ; Lloyd, ibid at 529.

See Roznai \& Mordechay, supra note 6; Sjöberg, supra note 6.

See Bailey, Burkell \& Reynolds, supra note 11 at 186.

See e.g. Katherine Alteneder \& Linda Rexer, "Consumer Centric Design: The Key to $100 \%$ Access" (2014) 16 JL in Soc'y 5 at 27-29 (discussing "digital divide" issues with respect to access to technology and technological literacy). 
justice and technology is neither necessary nor necessarily positive," 29 in that "innovations that enhance access to justice for some groups of beneficiaries may not assist, or could even come at the expense of, advances for other groups. ${ }^{30}$ For instance, although Internet access is widespread in Canada (a 2012 Statistics Canada showed 83 percent of individuals had Internet access at home, a number which has likely grown since),${ }^{31}$ not everyone is able to take full advantage of legal information made available online: persons with low literacy skills or low technological literacy, persons who are blind or who have visual impairments, or persons affected by poverty may have difficulty accessing online legal resources for various reasons. ${ }^{32}$

It is therefore crucial, when evaluating the access to justice impact of any technological measure, to consider whether the measure has unintended negative side effects, in particular for individuals that are members of groups that are already vulnerable or marginalized. Our study, which considers the extent to which court information made available online through Canadian court websites is accessible for persons who are blind or who have visual impairments, attempts to do precisely this. ${ }^{33}$ As such, this article contributes to the body of literature that emphasizes the need to ensure that any technological measures taken to promote access to justice do not unintentionally contribute to the marginalization of otherwise vulnerable groups. This approach is coherent with the social model of disability, which makes a distinction between "impairment" (the physical, sensory, or cognitive condition) and "disability" (how "society restricts [persons with impairments'] opportunities to participate in mainstream economic and social activities, rendering them more or less dependent"); this view emphasizes that barriers disabled persons face are societal and require societal solutions, rather than individualized ones. ${ }^{34}$

A number of authors have written about the specific access to justice challenges faced by marginalized groups, ${ }^{35}$ such as the relationship between technology and courtroom access

Bailey, Burkell \& Reynolds, supra note 11 at 183.

Ibid at 205.

Graham Reynolds, "The Role of Courts in Assisting Individuals in Realizing Their s. 2(b) Right to Information About Court Proceedings," in Karim Benyekhlef et al, eds, eAccess to Justice (Ottawa: University of Ottawa Press, 2016) 95 at 100, citing Statistics Canada, Canadian Internet Use Survey, 2012 at 1, online: <www.statcan.gc.ca/daily-quotidien/131126/dq131126d-eng.htm>.

2 Hughes notes the intersectionality of disability with poverty and other traits associated with exclusion from access to justice. See Hughes, "Generic Solutions," supra note 7 at 13-15. See also M David Lepofsky \& Randal NM Graham, "Universal Design in Legislation: Eliminating Barriers for People with Disabilities" (2009) 30:2 Stat L Rev 97 at 102-103 (describing issues that inaccessible websites and computer file formats can pose to users with visual disabilities, creating "informational barriers" that prevent these users from accessing publicly available information).

Given that most information on web pages is presented in the form of text, images, or video, individuals who are blind or who have visual impairments are particularly vulnerable to the presentation of online information in ways that are not accessible to them. For more on how users with visual disabilities use the web, see W3C, "Diversity of Web Users," online: <www.w3.org/WAI/intro/people-use-web/ diversity\#visual $>$.

See Michael Oliver \& Colin Barnes, The New Politics of Disablement, 2nd ed (Houndmills, UK: Palgrave MacMillan, 2012) at 21-23 (setting out the definition of the social model of disability and its concern with identifying "economic, environmental and cultural barriers," also addressing a number of criticisms of the model).

See Constance Backhouse, "What Is Access to Justice?" in Julia Bass, WA Bogart \& Frederick H Zemans, eds, Access to Justice for a New Century: The Way Forward (Toronto: Law Society of Upper Canada, 2005) 113. 
for individuals with disabilities, ${ }^{36}$ and the impact of internet usage on and the adoption of new technologies by elements of the justice system. ${ }^{37}$ However, the accessibility of court websites in particular has not been objectively assessed in a published article. This article adds to the literature by engaging in such an evaluation, thereby providing additional information for policymakers to help guide their decisions.

\section{Methodology}

As noted above, this study used two testing methods to evaluate the accessibility of court websites. First, informed by the Web Content Accessibility Guidelines (WCAG) 2.0, a set of guidelines developed as a single standard for the accessibility of web content for persons with disabilities, the co-authors used automated testing to evaluate court websites for accessibility problems. ${ }^{38}$ Second, after having secured research ethics approval, the coauthors worked with Access \& Diversity at UBC to recruit participants who are blind or who have visual impairments. Using task-based and holistic user testing, the co-authors gathered the experiences of these users with these same court websites. ${ }^{39}$ Pairing automated testing based on WCAG with user testing was a deliberate structural choice, informed by previous accessibility testing scholarship: while each testing method has its advantages and disadvantages (as detailed below), applying them together provides more fulsome coverage of accessibility issues than either would on their own.

\section{A. The Websites Tested: Canadian Courts And CanLII}

For the purposes of this study, ten websites were surveyed, namely the websites for the:

- $\quad$ Supreme Court of Canada, ${ }^{40}$

- Federal Court, ${ }^{41}$

- Federal Court of Appeal, ${ }^{42}$

- Provincial Court of British Columbia, ${ }^{43}$

- Supreme Court of British Columbia, ${ }^{44}$

- $\quad$ British Columbia Court of Appeal, ${ }^{45}$

See e.g. Peter Blanck, Ann Wilichowski \& James Schmeling, "Disability Civil Rights Law and Policy: Accessible Courtroom Technology" (2004) 12:3 Wm \& Mary Bill Rts J 825; Stephanie Ortoleva, "Inaccessible Justice: Human Rights, Persons With Disabilities and the Legal System" (2010) 17:2 ILSA J Intl \& Comp L 281.

$37 \quad$ See e.g. Karen Eltis, Courts, Litigants and the Digital Age: Law, Ethics and Practice (Toronto: Irwin Law, 2012); Jane Bailey \& Jacquelyn Burkell, "Implementing Technology in the Justice Sector: A Canadian Perspective" (2013) 11:2 CJLT 253.

38 See W3C, "WCAG 2.0," supra note 9.

39 A focus on the accessibility of online legal information for persons with visual disabilities in the usertesting portion of our study is justified in part because of the preponderance of visual content on the Internet. This is reflected in the wide array of assistive technologies which are available to visually impaired users: for example, screen readers, braille keyboards and readers, and screen magnification software. Supreme Court of Canada, "Welcome to the Supreme Court of Canada," online: <www.scc-csc.ca/ home-accueil/index-eng.aspx>.

$41 \quad$ Federal Court, "Welcome," online: $<$ cas-cdc-www02.cas-satj.gc.ca/portal/page/portal/fc_cf_en/Index $>$.

42 Federal Court of Appeal, "Welcome," online: <cas-cdc-www02.cas-satj.gc.ca/portal/page/portal/fcacaf_eng $>$.

43 Provincial Court of British Columbia, "Provincial Court of British Columbia," online: <www. provincialcourt.bc.ca/>.

44 The Courts of British Columbia, "Supreme Court," online: <www.courts.gov.bc.ca/supreme_court/>.

45 The Courts of British Columbia, “Court of Appeal," online: <www.courts.gov.bc.ca/Court_of_Appeal/>. 
- Ontario Court of Justice, ${ }^{46}$

- Ontario Superior Court of Justice, ${ }^{47}$

- Court of Appeal for Ontario, ${ }^{48}$ and

- CanLII. $^{49}$

These courts were chosen for the following reasons: the Supreme Court of Canada is the highest court in Canada (the court of last resort); the Federal Courts have exclusive or shared jurisdiction over matters in which individuals from any province or territory could become involved; and British Columbia and Ontario are the two most populous English-speaking jurisdictions in Canada. CanLII was chosen on the basis that a number of Canadian court websites either link to it or embed it on their sites rather than constructing, maintaining, and updating their own judgment databases. ${ }^{50}$

Court websites in particular were chosen because of the wide range of legal information that they make available, from basic information regarding the location of courts and their hours (information that is important for a variety of reasons, and particularly to selfrepresented litigants), to free, publicly accessible judgment databases. ${ }^{51}$

This article uses the terms "websites" and "web pages" throughout (also shortened to "sites" and "pages"). In this context, web page refers to the individual document usually delivered all at once to the user's browser. ${ }^{52}$ A collection of linked web pages constitutes a

46 Ontario Court of Justice, “Ontario Court of Justice," online: <www.ontariocourts.ca/ocj>.

47 Ontario Superior Court of Justice, "Superior Court of Justice," online: $<$ www.ontariocourts.ca/scj/>.

48 Court of Appeal for Ontario, "Court of Appeal for Ontario," online: <www.ontariocourts.ca/coa/en/>.

49 CanLII, supra note 1.

50 The British Columbia Provincial Court, Ontario's Court of Justice and Superior Court of Justice use CanLII for their judgment search functionality. Similarly, among Canadian courts not included in this study, the Alberta courts, Saskatchewan courts, Supreme Court of Newfoundland and Labrador (General Division), Supreme Court of Prince Edward Island, and the Prince Edward Island Court of Appeal rely on CanLII for judgment search: see Alberta Court of Queen's Bench, "Judgments," online: < https:// albertacourts.ca/court-of-queens-bench/judgments>; Alberta Court of Appeal, "Judgments," online: $<$ https://albertacourts.ca/court-of-appeal/judgments>; Alberta Provincial Court, "Judgments," online: $<$ https://albertacourts.ca/provincial-court/judgments>; Saskatchewan Law Courts, "Decisions," online: $<$ https://www.sasklawcourts.ca/home/decisions $>$; Supreme Court of Newfoundland and Labrador (General Division), “Judgments," online: <www.court.nl.ca/supreme/general/judgments.html>; Supreme Court of Prince Edward Island, "Court Decisions," online: <www.courts.pe.ca/supreme/index. php?number $=1050808 \&$ lang=E $>$; Prince Edward Island Court of Appeal, "Court of Appeal Decisions," online: $<$ www.courts.pe.ca/appeal/index.php?number=1039734\&lang=E $>$. The Yukon Court of Appeal, Supreme Court, Territorial Court, and Small Claims Court all link to CanLII for archived decisions: Yukon Courts, "Court of Appeal Judgments," online: <www.yukoncourts.ca/courts/appeal/2322.html>; Yukon Courts, "Supreme Court Judgments," online: <www.yukoncourts.ca/courts/supreme/ judgments.html>; Yukon Courts, "Territorial Court Judgments," online: <www.yukoncourts.ca/courts/ territorial/judgments.html>; Yukon Courts, "Small Claims Court Judgments," online: <www.yukon courts.ca/courts/smallclaims/3296.html $>$. As we note in the conclusions and recommendations section of the article, a broader study of accessibility compliance of judgment and statute databases and their usability for practitioners with disabilities may be warranted. Similarly, self-help legal resources that are directed towards the lay public are another potentially valuable object of study.

51 See Reynolds, supra note 31, Part 3 for further information about ways in which courts have taken advantage of technological developments to make legal information available to the public.

This definition is somewhat limited, but is sufficient for this article. See W3C, "Understanding Conformance," online: <https://www.w3.org/TR/UNDERSTANDING-WCAG20/conformance.html > [W3C, "Understanding Conformance"]. "Understanding Conformance" describes in more detail what can constitute a "web page" under WCAG's broader definition:

It is important to note that, in this standard, the term "Web page" includes much more than static HTML pages. The term "Web Page" was used in these guidelines to allow the guidelines to be more understandable. But the term has grown in meaning with advancing technologies to encompass a wide range of technologies, many of which are not at all "page-like". It also includes the increasingly dynamic Web pages that are emerging on the Web, including "pages" that can 
website. Many websites exist on a specific domain or subdomain (for example, the Supreme Court of Canada's website at www.scc-csc.ca would include all of the web pages under the domain "www.scc-csc.ca"), while others share a domain with other websites (for example, the Ontario Court of Appeal, Ontario Superior Court of Justice, and Ontario Court of Justice websites all exist under the ontariocourts.ca domain at ontariocourts.ca/coa, ontariocourts.ca/scj, and so forth).

However, the automated testing tool that we used for this study, the Functional Accessibility Evaluator (FAE) (described in more detail below), uses a more strict definition of "websites" which only recognizes the former usage (a collection of web pages under the same domain or subdomain). Therefore, in the automated testing section of our results, the Court of Appeal for Ontario, Ontario's Superior Court of Justice, and the Ontario Court of Justice are merged (collectively, "Ontario courts"), ${ }^{53}$ as are the British Columbia Supreme Court and Court of Appeal. For the user testing portion of our study, we treated each court as having a separate "website" in order to allow for more detailed feedback.

\section{B. Automated Testing}

\section{TESTING FRAMEWORK:}

\section{WEB CONTENT ACCESSIBILITY GUIDELINES 2.0}

Widely used by web developers and content providers, WCAG is a comprehensive set of accessibility guidelines for web content the purpose of which is to address accessibility concerns associated with a range of disabilities "including blindness and low vision, deafness and hearing loss, learning disabilities, cognitive limitations, limited movement, speech disabilities, photosensitivity and combinations of these." 54 Compliance with WCAG standards may also serve to make web pages easier to use for users without disabilities. ${ }^{55}$

Developed under the World Wide Web Consortium (W3C ${ }^{56}$ )'s Web Accessibility Initiative (WAI) "with a goal of providing a single shared standard for web content accessibility that meets the needs of individuals, organizations, and governments internationally," is organized into three "layers" - principles, guidelines, and success criteria. ${ }^{58}$ Each success

present entire virtual interactive communities. For example, the term "Web page" would include an immersive interactive movie-like experience that you find at a single URI.

53

Such, this shorthand is appropriate.

See ibid; Sven Schmutz, Andreas Sonderegger \& Juergen Sauer, "Implementing Recommendations From Web Accessibility Guidelines: Would They Also Provide Benefits to Nondisabled Users" (2016) 58:4 Human Factors 611.

56 The $\mathrm{W} 3 \mathrm{C}$ is an international standards organization "administered via a joint agreement among these 'Host Institutions': MIT, ERCIM, Keio University, and Beihang University": W3C, "Facts About W3C," online: <https://www.w3.org/Consortium/facts>. In addition to developing WCAG, W3C also maintains standards integral to the modern web such as HTML, CSS, and XML: W3C, "Standards," online: $<$ https://www.w3.org/standards/>.

${ }^{57}$ W3C, "Web Content Accessibility Guidelines (WCAG) Overview," online: $<$ https://www.w3.org/WAI/ intro/wcag.php>. See also Judy Brewer, "Standards Bodies, Access to Information Technology, and Human Rights" in Jonathan Lazar \& Michael Ashley Stein, eds, Disability, Human Rights, and Information Technology (Philadelphia: University of Pennsylvania Press, 2017) 11 at 16-17 (describing W3C's standards development process).

58 WCAG consists of 66 testable success criteria organized under 12 guidelines grouped into four broad principles. 
criteria is classified into one of three levels of conformance: A, AA, and AAA (with AAA being the highest). ${ }^{59}$ The levels of conformance are an important part of WCAG: In order to claim that a site or page meets a certain level of conformance, all of the success criteria under that level of conformance must be met. Claims to conformance at higher levels necessarily implies conformance at lower levels, with the result that a site or page cannot be AA conforming without being A conforming, and cannot be AAA conforming without being both AA and A conforming. WCAG also provides "sufficient techniques, advisory techniques, and documented common failures" ${ }^{60}$ in order to help illustrate problems and solutions for site providers.

There are a number of practical benefits to using WCAG as an accessibility standard. For example, WCAG's success criteria are designed to be testable. This ensures that the standard and the criteria for complying with the standard are sufficiently well-defined that WCAG can "be used where requirements and conformance testing are necessary," such as in regulation or in contracting for web design and development. ${ }^{61}$ As well, the standard can be applied to any website: ${ }^{62}$ the guidelines do not require the tester to identify how a site will be used and formulate tasks accordingly (such as finding a specific piece of information or accomplishing a specific task) as WCAG attempts to encompass accessibility issues wherever they might appear.

Other benefits include the fact that the standard is maintained by a prominent standards organization (W3C); that it is developed through a collaborative process involving a number of different stakeholders, and as such reflects the requirements and perspectives of different affected groups (including persons with disabilities as well as those that create and maintain web content); ${ }^{63}$ that, as stated in its introduction section, WCAG is a "stable, referenceable technical standard" that "is designed to apply broadly to different Web technologies now and in the future," relevant to new technologies; ${ }^{65}$ and that a number of the guidelines laid out by WCAG can be automatically tested, allowing hundreds of pages on a website to be tested for issues quickly and economically.

However, a number of criticisms of the WCAG standards have been raised. One study by Amaia Aizpurua, Simon Harper, and Markel Vigo, for instance, has questioned the link between compliance with WCAG standards and user experience, ${ }^{66}$ suggesting, for example,

See W3C, "Understanding Conformance," supra note 52. Success criteria have been assigned to different levels of conformance based on consideration of a number of factors, including whether the criterion is essential for assistive technologies to make content accessible, whether the criterion would impose limits on the appearance or function of web pages, and the difficulty in implementing the criterion. A criterion that is more essential, less limiting, and less difficult to implement would likely be assigned to a lower level of conformance.

Ibid.

One of the factors taken into consideration when assigning success criteria to conformance levels is whether it would be "possible to satisfy [WCAG] for all Web sites and types of content that [they] would apply to (e.g., different topics, types of content, types of Web technology)": W3C, "Understanding Conformance," supra note 52 [emphasis omitted]. AAA conformance may not be possible for all types of content, for instance.

See Brewer, supra note 57 at 16-17.

W3C, "WCAG 2.0," supra note 9.

Brewer, supra note 57 at 16-17.

Amaia Aizpurua, Simon Harper \& Markel Vigo, "Exploring the Relationship between Web Accessibility and User Experience" (2016) 91 Intl J Human-Computer Studies 13. 
that a site can fail to meet a number of WCAG success criteria, but still be usable for persons with disabilities, or comply with WCAG but still present obstacles to individual users' experience with the site. ${ }^{67}$ Sarah Lewthwaite has criticized WCAG's failure to take into account the cultural aspects of disability, arguing that the discourse around accessibility standards fails to "respect disability as a complex and culturally contingent interaction" or "recogniz[e] that disability is a variable, contrary, cultural and political power relation, rather than a biological limit." 68

Despite these criticisms, however, WCAG still provides a valuable framework for structuring and understanding the results of accessibility testing — particularly because it attempts to provide a comprehensive accounting of possible accessibility issues. While WCAG may not capture every accessibility issue or the nuance of users' experiences, supplementing WCAG with testing methodologies designed to elicit detailed feedback from users will help to offset the drawbacks just identified.

\section{Testing ToOL: FAE}

Although the guidelines and success criteria in WCAG inform how we have presented the results of our study, the actual testing was done using FAE. This free tool, developed at the University of Illinois at Urbana-Champaign, uses a series of automated tests to assess a website's functional accessibility, with each test relating to a WCAG success criterion. ${ }^{69}$ This provides a quick and free way of testing a large number of web pages for WCAG compliance.

FAE automatically evaluates each web page being tested on a number of rules. ${ }^{70}$ However, as an automated tool, it has certain limitations. For example, the tool can ascertain whether an image has alternative text associated with it, but not whether the text is an accurate and adequate representation of the image's contents. ${ }^{71}$ In these cases, FAE returns a result of "manual check," which indicates that it is "[u]nable to programmatically determine a result" and that "evaluation requires human inspection and knowledge of the associated WCAG 2.0

As Aizpurua, Harper \& Vigo have noted, in individual cases, failure to meet WCAG success criteria may be unrelated to the specific tasks users have in mind when visiting a website: see ibid.

68 Sarah Lewthwaite, "Web Accessibility Standards and Disability: Developing Critical Perspectives on Accessibility" (2014) 36:16 Disability \& Rehabilitation 1375 at 1381.

69 This is not necessarily a 1:1 relationship, however. While success criteria are relatively narrow, many of them can be fulfilled (or fail to be fulfilled) in more than one way; therefore, some success criteria have multiple corresponding tests in FAE.

70 See Functional Accessibility Evaluator 2.0, "HTML5 and ARIA Techniques," online: $<$ https://fae. disability.illinois.edu/rulesets/ruleset/ARIA STRICT/>. For example, the tool determines whether web pages use structural markup, such as HTML headings, which assist with navigation and contextual orientation. Tests for text equivalents determine whether text descriptions of non-text content such as images are present, while other rules test for scripts being used in a way that might compromise accessibility and interoperability - for example, scripted elements that do not support keyboard input would be difficult or impossible for users accessing the page through a screen reader to interact with. It is also worth noting that FAE has two rulesets: HTML5 and HTML4 Legacy. The sites in this study were tested with the HTML5 ruleset if the pages were identified as that document type, otherwise the HTML4 Legacy ruleset was used. The British Columbia Provincial Court, Supreme Court of Canada, and CanLII sites all identified as HTML5 and were tested using that ruleset; every other site was tested with the HTML4 Legacy ruleset.

71 Functional Accessibility Evaluator 2.0, "Alt Text Must Summarize Purpose," online: $<$ https://fae. disability.illinois.edu/rulesets/ruleset/ARIA STRICT/rule/IMAGE 2/>. 
requirement." 72 Therefore, full compliance of a website with WCAG cannot be verified without some manual testing.

Where FAE can programmatically determine a result for a given rule, it will return one of "violation" (where an element fails a rule that is required for compliance), "warning" (where an element fails a rule that is merely recommended for compliance), or "pass" (where all the requirements of a rule are satisfied).$^{73}$ This study focused primarily on violations, as these constitute unambiguous failures to comply with WCAG.

In addition, FAE cannot necessarily test every page on a website in one session: the tool can test a single page, follow all internal hyperlinks on one page (that is, hyperlinks pointing to pages on the same site), or follow all internal hyperlinks on one page and on all the pages linked to from that page. ${ }^{74}$ Pages on the same domain and subdomain are considered to be part of the same website, while pages on different domains or subdomains are not. ${ }^{75}$

Despite its limitations, however, automated testing allows for the testing of a large number of pages efficiently, automatically, and in a way that is repeatable. While this process will not identify all accessibility issues, showing that a site is not fully compliant with WCAG only requires finding some violations with FAE. ${ }^{76}$

\section{USER TESTING}

\section{TASK-BASED AND Holistic TESTING}

It is in part on the basis of the limitations and criticisms of both WCAG and automated testing using FAE, as described above, that the authors chose to pair automated testing with both task-based and holistic user testing. ${ }^{77}$ Task-based user testing involves asking users to complete tasks on a web page or site. Data is then collected which may include completion rates, site feedback, as well as other metrics. ${ }^{78}$ Holistic testing asks users to browse a web page and give general feedback on their experience. This study used a mix of both methods:

Functional Accessibility Evaluator 2.0, "Concepts and Terms," online: $<$ https://fae.disability.illinois. edu/abouts/concepts/>.

Ibid.

74 As such, pages on the site that are more than two links away from the starting point (usually the home page) will not be tested. If there are any pages which are not linked to at all on the site, these would have to be tested individually.

75 For example, a test on www.courts.gov.bc.ca would cover pages under www.courts.gov.bc.ca/supreme court/ and www.courts.gov.bc.ca/Court_of_Appeal/ but would not cover pages on www.provincial court.bc.ca.

76 However, it is worth noting that WCAG and FAE have contrasting approaches to evaluating accessibility. The WCAG success criteria and guidelines are essentially positive: they provide standards which web content providers should meet in order to make their websites accessible to users with disabilities. The tests that FAE runs are based on guidelines and success criteria that WCAG provides; however, in contrast to WCAG, these tests are essentially negative: FAE attempts to find instances where websites have content that fails to meet the WCAG success criteria and identifies these as accessibility "violations."

$77 \quad$ Task-based and holistic user testing can be contrasted with manual accessibility testing, which involves testers seeking out accessibility issues by using special software or by examining web pages' source code.

78 The type of data collected will depend on the level of granularity desired. Testing for accessibility problems with the aim of fixing said problems (that is, engaged in by the content provider) can benefit from more in-depth metrics which went beyond the scope of this study: see Part V.A.2, below. 
asking users both to "read and navigate [an] entire" page (holistic user testing), ${ }^{79}$ as well as to find specific pages or content and reflect on their experience (task-based user testing).

A range of benefits flow from the application of user testing as a methodology through which to evaluate website accessibility. ${ }^{80}$ User testing can provide a more nuanced account of the challenges faced by persons with disabilities, as testers can comment on whether they were able to successfully navigate the site and whether the accommodations the site makes for persons with disabilities are sufficient. As well, testers can identify usability issues that may fall outside the strict bounds of what is considered "accessibility" but which nevertheless impact users with disabilities.

On the other hand, user testing has some deficiencies which are important to acknowledge and to correct for. For instance, it may be expensive or otherwise difficult to recruit testers. Furthermore, the results of user testing are not necessarily repeatable, as different users will likely encounter different issues when using the same website. As well, task-based testing only has the benefit of being "true to users' experience" if the tasks that are formulated accurately reflect how users use the site. Another deficiency of user testing is that the assistive technologies used in testing may not be available to everyone, which might impact both the composition of the group of testers as well as any conclusions reached on the basis of the test data. ${ }^{81}$ Finally, the testing may capture issues outside of the core questions posed by the study. For example, in the context of court websites, difficulties in using the website may have to do in part with a lack of subject matter expertise (with regards to law). However, the goal of web accessibility standards is to make web content accessible; whether a given site meets these standards or not (a question that can be determined in part through automated testing) is secondary to whether the site is in fact accessible for users with disabilities. Only by actually involving users with disabilities in the testing process can this question be adequately answered.

\section{PARTICIPANTS}

The ten sites described above were tested between March and June 2015 by a group of six users who have visual impairments. Four users employed "JAWS," a popular screen reader, ${ }^{82}$

79 See Appendix II, below.

80 As noted above, WCAG contemplates a number of other impairments including cognitive and physical impairments. While it was not feasible for this study to conduct representative user testing for all of these groups, the broad scope of WCAG — which our automated testing made use of — should nevertheless provide an indication of accessibility issues for these groups.

81 See e.g. the high cost of "JAWS," a popular screen reader used by a number of participants in this study: Freedom Scientific eStore, "JAWS Home Edition Screen Reader," online: < https://store.freedom scientific.com/products/jaws-home-edition-screen-reader> (showing the "Home Edition" of the software selling for nearly \$900). However, these or similar assistive devices may be covered by programs such as Ontario's Assistive Device Program: see e.g. Government of Ontario, "Assistive Devices Program," online: $<$ https://www.ontario.ca/page/assistive-devices-program $>$.

82 It is worth noting that being accessible only to relatively high-end software like JAWS is insufficient to make a site accessible: such software is expensive enough to be unavailable to many users. See "JAWS Home Edition Screen Reader," ibid; Jodhan, supra note 9 at para 13. See also W3C, "Understanding Conformance," supra note 52, where the W3C also comments on this issue: "Support by just one assistive technology (for a given disability) would not usually be enough [to make a site accessible], especially if most users who need it in order to access content do not have and cannot afford that assistive technology." The W3C also acknowledges, however, that current free and low-cost accessibility technologies lack crucial functionality, and that it would be unrealistic to require websites to be totally accessible to the "lowest (or even middle) common denominator" (ibid). 
while two users employed "ZoomText," a screen magnifier with a built-in text-to-speech function. ${ }^{83}$ All participants were either alumni or students of $\mathrm{UBC},{ }^{84}$ were recruited through Access \& Diversity at UBC, and had over five years' experience with assistive technologies. Five users indicated their average computer usage to be over three hours per day, while one user indicated an average of between one and three hours. None of the users indicated that they had experience with Canadian court websites.

\section{RESPONSE FORMAT}

In the user testing portion of our study, we asked participants to record their responses in two formats: numerical ratings of each page or task using the five-point "Thompson scale" $(0-4)$ (described in more detail below), and open-ended, qualitative comments in which users described their experience. Users reported their results by completing a survey made available in both paper form and online through the UBC Survey Tool. ${ }^{85}$

Developed in a 2003 paper by Terrill Thompson, Sheryl Burgstahler, and Dan Comden, the five-point "Thompson scale" aims to measure a web page's functional accessibility. ${ }^{86}$ Each score is intended to correspond to a certain level of ease or difficulty with which the user could perform the task. Users were given an explanation of the scores as follows:

- If the user could perform the intended function(s) easily, the web page or task would receive a rating of four.

- A rating of three indicates that the user could perform the intended function(s) despite the web page(s) failing to comply with all accessibility guidelines.

- A page or task with obvious accessibility problems, but which skilled users could nevertheless, with patience, navigate to perform intended functions, would be assigned a rating of two.

- A rating of one indicates significant accessibility problems that could be overcome only with considerable difficulty.

- $\quad$ Finally, a web page that is entirely inaccessible (that is, where the user was unable to perform intended function(s) without assistance), would be assigned a rating of zero. $^{87}$

86

ZoomText, “ZoomText Magnifier/Reader," online:<www.zoomtext.com/products/zoomtext-magnifier reader/>.

It is important to recognize that the fact that the participants were students or alumni of the University of British Columbia has implications with regard to education level, literacy, digital literacy, income, and socio-economic background. Therefore, the sample may not be representative of users with visual impairments generally; however, many of the issues faced by the participants when testing the subject websites are likely to affect other users with visual impairments.

UBC Information Technology,"UBC Survey Tool,” online: <it.ubc.ca/services/teaching-learning-tools/ survey-tool>.

Terrill Thompson, Sheryl Burgstahler \& Dan Comden, "Research on Web Accessibility in Higher Education" (2003) 9:2 Information Technology \& Disabilities J. The paper uses the now-obsolete WCAG 1.0 standard, but the accessibility objectives expressed in the five-point scale remain relevant to current-day accessibility testing. Ibid. 
In addition, users' comments were coded based on the accessibility issues mentioned, and the results of this process were tallied. ${ }^{88}$ The first round of coding involved both analyzing the comments to draw out common issues and counting the number of reports of each issue, by site and by page. The success criteria in WCAG helped inform the initial identification of accessibility issues, but the coding did not take those as a priori categories. Multiple issues could be reported in a single comment; however, only comments that explicitly reported no issues were counted as "no problems" (see results section below) ${ }^{89}$ The second round revisited the comment data using the same classifications of issues that were extracted in the first round. The two datasets were then reconciled by individually reassessing each comment where there was a discrepancy between the two.

\section{Results}

\section{A. Automated Test Results}

Automated testing with FAE found WCAG violations on all of the websites surveyed. The FAE tool tallies the number of rules violated rather than the number of individual rule violations. For instance, a site with multiple images that lack alternative text, assuming that this is the only rule violated, would only count as having one violation. Therefore, the number of pages surveyed from each of the sites was only a factor in terms of the overall result insofar as more content offers more opportunities for WCAG guidelines to be violated.

The FAE tool provided reports on each website surveyed as well as on individual pages. The results showed an average of 4.17 violations per page, and 10.14 violations per site. Approximately 14 percent of the violations were of WCAG AA guidelines while the remaining 86 percent were of WCAG A guidelines. "A" guidelines are the lowest standard for accessibility; therefore, violations of these guidelines are potentially more serious than violations of AA or AAA guidelines. ${ }^{90}$

Using WCAG principles and guidelines to categorize the violations reported by FAE helps to illustrate what accessibility issues affect these sites. Many of the most common violations found related to insufficient or incorrectly organized structural information that may hamper the ability of users to navigate and understand web pages' content using assistive technologies: rows 1.3, 2.4, and 3.3 in Table 1 are examples of this. ${ }^{91}$ However, a range of other issues were found as well, including violations under each of the guidelines in WCAG except 2.2 and 2.3. Each of the WCAG guidelines will be explored in more depth below. ${ }^{92}$

For a description of coding methodology, see Robert Thornberg \& Kathy Charmaz, "Grounded Theory and Theoretical Coding" in Uwe Flick, ed, The SAGE Handbook of Qualitative Data Analysis (London: SAGE, 2014) 153.

89 For example, a comment that reported the user having no issues accessing the content, but noting that the site could improve its accessibility by adding alternative text to its images would be counted as one report of "lack of alternative text," and not counted as "no problems." Similarly, blank comments were not counted as reports of "no problems."

90 For a discussion of WCAG conformance levels, see Part III.B.1, above.

91 See Appendix I, Table 1, below. See also "Access to Justice Online: Supplement," online: <www.allard. ubc.ca/sites/www.allard.ubc.ca/files/uploads/Rei-Anderson_et_al_A2J_Online_Supplement.pdf $>$ (presenting tables in Appendix I in an accessible format).

92 Note that there are, in many cases, multiple FAE rules assigned to a single success criterion, each denoting one way in which web content can fail to meet that success criterion: see Functional Accessibility Evaluator 2.0, "Rulesets," online: <https://fae.disability.illinois.edu/rulesets/wcag/>. The numbers in this chart correspond to the number of FAE rules violated according to our testing, not the 


\section{PRINCIPLE 1: PERCEIVABLE}

The WCAG principle of perceivability requires that information and interface be presented in ways that users can perceive, whether through a web browser or using assistive technology. ${ }^{93}$

\section{i. $\quad$ Guideline 1.1: Text Alternatives}

This guideline requires that websites "[p]rovide text alternatives for any non-text content so that it can be changed into other forms people need, such as large print, braille, speech, symbols or simpler language." ${ }^{94}$ Our study found violations under this guideline in three of the sites tested: the Supreme Court of British Columbia, the British Columbia Court of Appeal, the Provincial Court of British Columbia and Ontario courts. The most common issue under this guideline is the failure of site providers to add alternative text describing images; in our study, all three sites for which violations were found under this guideline had this issue on at least one page.

\section{ii. $\quad$ Guideline 1.2: Time-Based Media}

Websites must "[p]rovide alternatives for time-based media" to satisfy this guideline. ${ }^{95}$ "Time-based media" includes content that is audio-only, video-only, audio-video, or audio and/or video combined with interaction, all of which can present issues for users with disabilities. ${ }^{96}$ Content that relies on video presents obvious problems for users with visual impairments. Therefore, the inclusion of an alternative - such as an audio description track - is required to make such content accessible to users with disabilities. None of the tested sites had any time-based violations detected by FAE. The lack of video or audio content on Canadian court websites - aside from the Supreme Court of Canada webcasts, for which the videos themselves were not tested - means that rules in this category were unlikely to be violated.

\section{iii. $\quad$ Guideline 1.3: Adaptable}

This guideline requires that a website's content be such that it "can be presented in different ways (for example simpler layout) without losing information or structure." 97 This means, for example, that pages should use HTML markup for headings and other structural elements rather than merely making them visually distinct. HTML markup specifies different "tags" for headings and body text. When these tags are used properly, it allows screen reader users to browse through a list of the headings on a page (assuming the screen reader supports that functionality), which in turn makes it easier for users with visual impairments to navigate the page.

number of success criteria that were not met.

W3C, "How to Meet WCAG 2.0," online: <https://www.w3.org/WAI/WCAG20/quickref/> [W3C, "Meeting WCAG 2.0"].

Ibid.

Ibid.

W3C, "Understanding Guideline 1.2 [Time-based Media]," online: <https://www.w3.org/TR/UNDER STANDING-WCAG20/media-equiv.html>.

W3C, "Meeting WCAG 2.0," supra note 93. 
Six of the tested sites had at least one violation detected by FAE under this guideline: the Provincial Court of British Columbia, Federal Court, Federal Court of Appeal, Ontario courts, Supreme Court of Canada, and CanLII. Issues included structural markup problems that make it difficult or fail to facilitate programmatic determination of the relationships between information on the page - for example, not using appropriate headings, or failing to use landmarks. ${ }^{98}$ The failure to use appropriate structural markup effectively means that screen readers cannot easily pick out headings and content areas; this has the potential to make web pages more difficult or time-consuming to navigate for users employing these assistive technologies.

\section{iv. $\quad$ Guideline 1.4: Distinguishable}

Under this guideline, the design of a website should "[m]ake it easier for users to see and hear content"; the success criteria deal with the distinguishability of content based on foreground-background colour contrast, as well as the volume of background audio. ${ }^{99}$ Four of the tested sites returned violations under this guideline: the Provincial Court of British Columbia, Federal Court, Federal Court of Appeal, and CanLII. These violations consisted of issues with colour contrast between foreground and background.

\section{PRINCIPLE 2: OPERABLE}

The guidelines and success criteria under the principle of operability aim to ensure that users with disabilities can make use of all the functions of a website that are available to a non-disabled user.

\section{i. $\quad$ Guideline 2.1: Keyboard Accessibility}

In order to accommodate, for example, users of screen readers for whom mouse control is not available, all of a website's functionality should be available by using a keyboard. ${ }^{100}$ The Supreme Court of Canada site was the only site for which FAE found any violations under this guideline, as the Supreme Court's webcasts page seems to lack keyboard controls.

\section{ii. $\quad$ Guideline 2.2: Enough Time}

This guideline advises that users should be provided "enough time to read and use content." 101 None of the tested sites had violations under this guideline, as there are no complex forms or other elements that might have a time limit.

See e.g. the websites for the British Columbia Supreme Court and Court of Appeal, which do not use HTML headings.

99 W3C, "Meeting WCAG 2.0," supra note 93.

100 In acknowledgment of the fact that this may not be possible for all website functions, there is a level A success criterion in 2.1.1 that excepts situations where "the underlying function requires input that depends on the path of the user's movement and not just the endpoints." The AAA level success criterion 2.1.3 is a more strict version of this criterion and lacks this exception. See ibid.

101 W3C, "Understanding Guideline 2.2 [Enough Time]," online: <https://www.w3.org/TR/UNDER STANDING-WCAG20/time-limits.html>. 


\section{iii. $\quad$ Guideline 2.3: Content That Can Cause Seizures}

Content should not be designed "in a way that is known to cause seizures" — in particular, "flashing visual content." 102 None of the tested sites had a violation under this guideline. As noted above, aside from the Supreme Court's webcasts (which were not themselves tested), none of the sites surveyed contained video or significant animations.

\section{iv. $\quad$ Guideline 2.4: Navigable}

Navigation has two main functions: "to tell the user where they are" and "to enable the user to go somewhere else." 103 As such, the success criteria under this guideline aim to ensure that users with disabilities are able to navigate websites. To comply with this guideline, websites should "[p]rovide ways to help users navigate, find content, and determine where they are." ${ }^{\prime 104}$ FAE testing found violations under this guideline on five sites: British Columbia's Supreme Court, Court of Appeal and Provincial Court, the Ontario courts, the Supreme Court of Canada, and CanLII. Examples of violations under this guideline are link text failing to describe where the link points (an important accommodation for screen readers) (2.4.4) and having more than one "banner" landmark on a page (2.4.1). This would impede screen readers from identifying the banner area of the page, which contains "site-oriented content ... such as the logo or identity of the site sponsor, and sitespecific search tool," and as such may make navigation of the page more difficult for users employing screen readers. ${ }^{105}$

\section{PRINCIPLE 3: UnderstandABlE}

The guidelines under this principle are meant to ensure that "[i]nformation and the operation of user interface [are] understandable." 106

\section{i. $\quad$ Guideline 3.1: Readable}

Under this guideline, "text content [should be] readable and understandable."107 The success criteria for this guideline require the web content provider to indicate the natural language ${ }^{108}$ of content to web browsers and assistive technologies. The highest level (AAA) criteria for this guideline also provide that websites should provide users assistance with technical or otherwise unusual language, abbreviations, pronunciation, and where the reading level of the content is above a certain level. Four sites (namely the websites for British

W3C, "Understanding Guideline 2.3 [Seizures]," online: $<$ https://www.w3.org/TR/UNDERSTAND ING-WCAG20/seizure.html>.

W3C, "Understanding Guideline 2.4 [Navigable]," online: $<$ https://www.w3.org/TR/UNDERSTAND ING-WCAG20/navigation-mechanisms.html> [W3C, "Understanding 2.4"], citing "Motive Web Design Glossary," online: <web.archive.org/web/20170111072803/http://www.motive.co.nz/glossary/navig ation.php>.

W3C," "Understanding Guidline 2.4," ibid.

W3C, "Banner Landmark: ARIA Landmarks Example," online: <https://www.w3.org/TR/wai-ariapractices/examples/landmarks/banner.html .

W3C, "WCAG 2.0," supra note 9.

W3C, "Understanding Guideline 3.1 [Readable]," online: <www.w3.org/TR/UNDERSTANDING$\mathrm{WCAG} 20 /$ meaning.html $>$.

"Natural language" referring to, for example, English or French, as opposed to markup or programming language. 
Columbia's Supreme Court, Court of Appeal and Provincial Court, the Ontario courts, and CanLII) had violations under this guideline, all of which were failures to include language codes to indicate the language of the page (3.1.1) (for example, as English).

\section{ii. $\quad$ Guideline 3.2: Predictable}

This guideline indicates that "[w]eb pages [should] appear and operate in predictable ways." "109 This includes avoiding the use of elements on a page which change the context (that is, what web page elements are visible and how they appear). ${ }^{110}$ This is important for accessibility in part because "screen readers present content as a one-dimensional stream of synthetic speech," "111 which makes it difficult to tell when the context has changed. The higher level (AA) criteria under this guideline deal with consistency in navigation and identification of elements. Two of the tested sites were found to have violations under this guideline: British Columbia's Supreme Court and Court of Appeal, and the Ontario courts' websites. The issues found included failures to use consistent headings for "recurring page sections common across all pages in [the] website"; this failure makes navigation on these pages more difficult by not providing users with similar "signposts" (for example, headings indicating the search bar or the site navigation bar on a page) across the site. ${ }^{112}$

\section{iii. $\quad$ Guideline 3.3: Input Assistance}

This guideline sets standards for web forms where users are expected to input information. Specifically, web forms should be constructed in such a way as to "[h]elp users avoid and correct mistakes." 113 WCAG has particular requirements for forms which incur legal commitments or for financial transactions (3.3.4), as well as general rules for all web forms, including search forms, login forms, and so on. FAE found violations under this guideline for all of the tested sites. This can largely be attributed to web form fields lacking labels that indicate what the user is expected to input (such as "Case name," or "Date"). ${ }^{14}$ These forms may have visible text indicating this to the user, but not a label element that would allow screen readers to associate descriptive text with a particular field. This would make it more difficult for a screen reader user to navigate and complete a web form. All of the websites' judgment search pages, save for the Supreme Court of Canada, had a violation of this nature (3.3.2).

\section{PRINCIPLE 4: ROBUST}

In the context of WCAG, "robustness" means that content should "be robust enough that it can be interpreted reliably by a wide variety of user agents, including assistive technologies." 115

W3C, “Understanding Guideline 3.2 [Predictable]," online: < https://www.w3.org/TR/UNDERSTAND ING-WCAG20/consistent-behavior.html>. See ibid.

Ibid.

See Functional Accessibility Evaluator 2.0, "Consistent h1 and h2 Page Section Labels," online: $<$ https://fae.disability.illinois.edu/rulesets/NAVIGATION_5/>.

W3C, "Understanding Guideline 3.3 [Input Assistance],"”- online: <https://www.w3.org/TR/UNDER STANDING-WCAG20/minimize-error.html>.

"Web form elements" includes most web page elements that accept user input, such as search boxes. W3C, "WCAG 2.0," supra note 9. 
Under this guideline, websites should "[m]aximize compatibility with current and future user agents, including assistive technologies." "Web browsers are another type of user agent.) For example, web pages should adhere to the HTML specification by not using tags that are deprecated; ${ }^{117}$ otherwise, the page or site would not meet this success criteria (although depending on the issue it may only return a warning from FAE rather than a violation $^{118}$ ), as it might generate compatibility issues such as inconsistent display of page elements across different user agents. These might affect traditional web browsers as well as assistive technologies. Given the wide range of possible deviations from the HTML specification, ${ }^{119}$ this guideline encompasses many possible accessibility problems. Four sites were found to have violations under this guideline: the websites for British Columbia's Supreme Court, Court of Appeal, Provincial Court, the Ontario courts, and the Supreme Court of Canada.

\section{B. USER TeSt Results}

\section{THOMPSON SCALE SCORES}

For all of the court websites, users were asked to navigate the homepage, find and evaluate the contact page, and search for a specific judgment. ${ }^{120}$ The Supreme Court of Canada website was tested similarly, but included a test of the "Webcasts" page which asked the users to navigate to that page and watch a video.

All of the sites except CanLII received an average of between three and four on the fivepoint Thompson scale (four being fully accessible), indicating that users found the sites to be reasonably accessible despite not wholly adhering to accessibility guidelines. These results are shown in Table $2 .^{121}$ Although CanLII received the lowest combined average score, ${ }^{122}$ the user tests on that site included only searches for specific decisions, whereas the other user tests included evaluating the accessibility of the sites' respective home pages and the pages indicating the court's address and contact information. ${ }^{123}$

W3C, "Understanding Guideline 4.1 [Compatible]," online: <www.w3.org/TR/UNDERSTANDINGWCAG20/ensure-compat.html>.

117 See ibid. Deprecated tags and other "deprecated features of W3C technologies" are features which were at one point included in the HTML specification (or another W3C specification), but which are no longer included (though they may still be supported by browsers and other user agents).

As an example, the HTML tags for bold and italic text are generally not to be used where the purpose is to emphasize or highlight text. However, the use of these tags is still prevalent and is accommodated by modern web browsers. The use of these tags only generates a "warning" from FAE.

This guideline would cover failures to adhere to the HTML specification such as "elements [without] complete start and end tags, elements [not] nested according to their specifications, elements ... contain[ing] duplicate attributes, and [non-unique] IDs ... except where the [specification] allow[s] these features": W3C, "WCAG 2.0," supra note 9.

Since CanLII is not a court website, the tests for that site were structured around finding a specific case using a style of cause and citation, and finding cases dealing with a particular topic using the keyword search function.

See Appendix I, Table 2, below; “Access to Justice Online: Supplement," supra note 91.

Since CanLII's primary function is searching and browsing judgments, this alteration of the test was appropriate. 
Furthermore, users gave at least one zero result (unable to access the desired content) as feedback to tests on three sites, ${ }^{124}$ and all sites except the Federal Court received at least one result at or below two (where a result of two indicates obvious accessibility problems, but tasks could be accomplished with patience or considerable difficulty). These results suggest that many of the sites tested, although reasonably accessible, could still benefit from accessibility improvements. Of the three pages tested for all nine of the court websites (the homepage, contact page, and the judgment search), the judgment search functionality had the lowest average accessibility rating. ${ }^{125}$ As well, the search tasks on CanLII received a significantly lower average score than the average accessibility rating for the courts' judgment search functionality.

\section{USER COMMENTS}

Comments were elicited for each of the pages tested by the six user participants, as well as overall comments for users' experience of the site as a whole. The comments elicited from users provide insight into the specific experiences of these users in completing the assigned tasks. Some of the issues encountered by users, while they amount to failures to meet WCAG success criteria, nevertheless did not prevent users from accomplishing the assigned tasks. For example, a lack of alternative text for images amounts to a failure of A-level success criteria 1.1.1, but did not necessarily correspond to low Thompson-scale scores in user feedback. This result highlights an important contrast between automated and user testing (as well as a limitation of automated testing). While automated testing highlights potential accessibility issues that may not actually significantly hamper a user's ability to use the site, user testing takes into account users' abilities to work around issues.

Other comments, however, highlight some of the limitations of user testing. For example, some feedback about the same web pages appears to be contradictory: while one ZoomText user found the colour contrast on the British Columbia Supreme Court search page to be an issue, the other ZoomText user specifically remarked on the contrast being good. In these situations, WCAG can provide objective criteria for accessibility: to continue the same example, success criteria 1.4.3 specifies acceptable colour contrast as being a ratio ${ }^{126}$ of at least 4.5:1 for A-level conformance, and success criteria 1.4.6 requires at least 7:1 for AAA conformance. Web pages either fail or do not fail these criteria.

Users' comments were coded for different kinds of feedback or issues encountered. The results of this coding appear in Table 5. ${ }^{127}$

See Appendix I, Table 3, below; "Access to Justice Online: Supplement," supra note 91. These sites were the Supreme Court of Canada (one result for the webcast page), the Ontario Court of Appeal (one each for the judgment search task and contact page), and CanLII (one result for searching a judgment by keywords).

126 See W3C, "Appendix A: Glossary," online: <www.w3.org/TR/WCAG20/\#glossary> (stating that the "contrast ratio" is defined as " $(\mathrm{L} 1+0.05) /(\mathrm{L} 2+0.05)$, where $\mathrm{L} 1$ is the relative luminance of the lighter of the colors, and L2 is the relative luminance of the darker of the colors"). 


\section{i. $\quad$ No Problems}

Users explicitly reported no problems with the website or with completing the task in 76 comments. Blank responses are not included in this tally. Furthermore, all sites tested had at least some comments that indicated no problems. Out of the sites surveyed, the site for the Supreme Court of Canada had the most "no problems" comments (16), while CanLII had the least at five. It is worth noting that the SCC also had the most prompts for comments, in that users were asked for feedback on four tasks as well as the site as a whole, while CanLII had the fewest, with users being asked for feedback on two tasks as well as the site as a whole. These results suggest that even with the various accessibility problems identified by automated testing and by users, participants were still able to complete a number of tasks without issue. However, as can be observed in Table 5, every site except the Federal Court, Federal Court of Appeal, and the Supreme Court of Canada had more reports of accessibility issues than comments indicating no problems with accessing the content. ${ }^{128}$

\section{ii. $\quad$ Search Design}

Twenty-five comments described an issue with the websites' search functionality. ${ }^{129}$ These comments indicated problems with how the search functions were designed, as opposed to issues with finding specific content. The sites which drew these comments were those for the British Columbia Provincial Court, Federal Court of Appeal, Ontario Court of Appeal, Ontario Court of Justice, and Ontario Superior Court of Justice, as well as CanLII. Aside from the Federal Court of Appeal and the Ontario Court of Appeal, these court websites all employ CanLII, either integrated into the site or via an external link, and a number of comments specifically noted that the CanLII search caused them issues because of its use of dynamically updating search results (that is, search results that begin populating while the user is typing). One such comment from a user employing JAWS noted that "[CanLII] uses dynamic content as you are typing a search query and it is not clear to me how to interact with that dynamic content. It looks like the citation I wanted was displayed dynamically, but it was not a proper link and I did not readily find a method for clicking on it."

\section{iii. No "Skip to Content" Link or “To Top" Link}

Twenty-four comments in total reported that pages did not have a "skip to content" link or "to top" link, or that one of these links was included but did not work. A "skip to content" link at or near the top of the web page content allows users employing screen readers to skip to the main part of the web page content, past navigation and other page elements that would otherwise take time to read through. Similarly, a "to top" link allows users to skip back to the top of the page. One JAWS user commented on the Federal Court Contact page that its inclusion of "'Skip to content' and 'Top of Page' links" made it "very efficient for locating information quickly." The absence of these accommodations make it more difficult and timeconsuming for screen reader users to complete tasks on the page. Users reported this issue

128 Ibid. The Federal Court and Federal Court of Appeal also had the fewest violations identified by FAE, and both had high average Thompson scores (the Federal Court in particular scoring the highest of all sites surveyed). This is a laudable result and these courts should be commended for their efforts in making their web content accessible.

129 As noted above, for each site, participants were provided with a citation and style of cause, and were asked to locate a judgment using the site's judgment search. 
on seven sites: the sites for British Columbia's Court of Appeal, Provincial Court, and Supreme Court, the Federal Court, and Ontario's Court of Appeal, Court of Justice and Superior Court of Justice.

\section{iv. Insufficient Labels}

Twenty-four total comments mentioned poor or missing labels, for example, for search forms or navigational controls. This issue (also discussed with respect to Guideline 3.3, above) is distinct from a lack of alternative text because it deals with how users interact with the page rather than the content of website elements. A JAWS user on the British Columbia Supreme Court Search task commented that on that page "not all elements are clearly labelled, using proper HTML tags for forms" and elaborated that for a screen reader user "[t]his means as you use the TAB KEY to move through the form, not all the controls will be announced with a clear label" and that these users "will have to [navigate] around the page to figure out what these form fields are supposed to do." The sites for British Columbia's Provincial and Supreme Courts, the Federal Court, Federal Court of Appeal, Ontario's Court of Appeal, Court of Justice, and Superior Court of Justice, the Supreme Court of Canada, and CanLII all had comments to this effect.

\section{v. Poor Contrast}

Twenty-one comments cited issues with colour contrast that made text on the web page difficult to read. This may be an issue for users with visual impairments that do not amount to full blindness, for instance those using assistive technology such as ZoomText. One user commented on the British Columbia Provincial Court Contact page that "[ $\mathrm{t}]$ he font colour to background did not have a strong contrast so I had trouble reading the text as I can only detect minimal pastel colours. I had to use ZoomText mouse over speech to confirm the link." The seven sites which were cited for poor contrast were those for British Columbia's Court of Appeal, Provincial Court and Supreme Court, CanLII, and Ontario's Court of Appeal, Court of Justice and Superior Court of Justice.

\section{vi. Lacking Alternative Text}

Twenty comments described an issue with alternative text (either that the text provided was inadequate or that it was altogether absent). Every site except CanLII had at least one complaint on this issue. As discussed in Part IV.A.1.i, above, the failure to provide adequate alternative text for non-decorative visual content is an accessibility issue. User testing allows for more detailed data on this issue than FAE, which is unable to detect when alternative text is insufficient to describe an image. As noted above, FAE only reports, as a violation, the absence of alternative text. However, even in the context of user testing it can be difficult to say what alternative text would be "adequate" in any given instance. For example, comments from two different users on the Supreme Court of Canada homepage were at odds: one user felt that a description of the image in addition to the photo credit and subject was warranted, while another was satisfied with the information that was provided. 


\section{vii. $\quad$ Structural Issues}

Eleven comments related to structural issues on the sites of British Columbia's Court of Appeal and Supreme Court, the Federal Court and Federal Court of Appeal, Ontario's Court of Appeal, Court of Justice and the Supreme Court of Canada. These included improper use of or failure to use HTML headings. One JAWS user commented on this issue appearing on the British Columbia Supreme Court homepage, writing that headings on that page were "printed in bold font, but [not] actually formatted as a proper HTML heading." The result was that screen readers couldn't "simply jump from heading to heading with a keystroke," making navigation on that page more difficult.

\section{viii. $\quad$ Video Plugin Issues}

Seven comments expressed issues with video plugins when accessing the webcasts on the Supreme Court of Canada website. Specifically, user comments expressed issues with the software (the Supreme Court's webcast page employs Microsoft Silverlight video) pertaining both to accessibility (unlabelled player controls) and compatibility (poor support for Mac OS $\mathrm{X}$ and Google Chrome). Five out of the six users expressed difficulty accessing the webcast, with one user unable to view it at all. One comment from a JAWS user summed up the accessibility challenges with the Silverlight video player:

In Windows, the Silverlight video player has significant accessibility challenges. The video plays and audio can be heard, but all of the player controls are unlabeled. You must simply try each one to see what it does as there is no accessible text label telling you what it will do. Some of the controls, of course, have functions which are obvious, such as skipping backwards and forwards through the webcast. These can be memorized by trial and error. I'm disappointed that in this day and age the Court is still using Silverlight rather than embracing an open standard like HTML5. This means the videos will not play on iOS devices. Also, to the best of my knowledge, Silverlight doesn't offer any accessibility at all on the Mac. This means a blind user would likely be able to hear the video, but would have no way to access the player controls.

\section{ix. $\quad$ Other Issues}

A number of issues were discrete and identifiable, but were only described in a few instances.

- $\quad$ Four comments related to links having the same text, which can be confusing for users of screen readers which generally have a function to browse through the links on a page. British Columbia's Court of Appeal, Supreme Court and the Supreme Court of Canada sites received comments to this effect.

- Two comments indicated that the search tasks which participants were asked to complete when evaluating CanLII were made difficult by a lack of subject area knowledge.

- The British Columbia Supreme Court and Provincial Court websites received one comment each taking issue with a use of a pop-up window for some information. 
- $\quad$ Finally, two comments described unpredictable behaviour on the Ontario Court of Appeal and British Columbia Provincial Court websites.

\section{x. $\quad$ Issues That Are Difficult to Classify}

There were two user comments that described issues with completing the tasks or navigating the webpages, but for which it could not be definitively determined what issue the participants encountered. The sites for CanLII and the Ontario Court of Appeal had reports of this nature.

\section{CONCLUSIONS AND RECOMMENDATIONS}

Based on the results of our study, we have reached the following conclusions. First, that the specific court websites tested (along with CanLII) are largely accessible, but fall short of best practices in a number of different ways. Second, that pairing automated testing with user testing, in the context of evaluating the accessibility of court websites, helps to provide a more nuanced picture of the ways in which websites might fail to meet best practices but still remain largely accessible. Third, further accessibility testing of different online legal materials, using additional testing methodologies and aimed at different affected groups, is desirable. Building from these conclusions, we make the following recommendations.

\section{A. Court Websites}

\section{TESTING SHOULd OCCUR REGULARLy}

While this study highlighted a number of issues in its survey of Canadian court websites, further testing of court websites should be done with the goal of addressing accessibility issues for people who are blind or who have visual impairments. We recommend that accessibility testing occur on a periodic basis or when sites undergo major changes. Periodic automated testing would help ensure that site content remains accessible with minor, day-today changes. More extensive testing should accompany major changes to a website: for example, a site redesign or reorganization. ${ }^{130}$

\section{Testing Should Gather More Detailed INFORMATION, WHERE APPROPRIATE}

In addition to the qualitative comments and overall accessibility ratings collected by this study, user testing can also collect data on other relevant metrics. For example, specialized testing software can gather data on the time it takes users to complete given tasks, the completion rates of various tasks, how many "clicks" it takes a user to complete a task, and the specific actions a user undertakes to complete a task. This kind of granular user data can be used to assist content providers both in identifying specific issues to fix in order to better meet accessibility needs, as well as in determining which issues to prioritize. As such, this type of data (as well as testing methodologies that allow for more detailed data collection

130 For example, major changes to site content, structure, or presentation and site design may necessitate more intensive testing. 
more generally) can be quite useful for site content providers looking to make their content more accessible.

\section{B. Benefits of Pairing Automated And User Testing}

The results of this study show the value of using both automated and user testing in seeking to evaluate the accessibility of online legal information. Automated testing and user testing complement each other. FAE and similar automated testing tools are quick and easy to use, and will detect at least some of the accessibility issues present on the pages they test. Adoption of regular testing using automated testing tools could thus provide significant accessibility benefits at relatively low cost. User testing, on the other hand, ensures that users with disabilities can provide feedback on their individual experiences. This goes some distance towards addressing the concerns raised by Lewthwaite with respect to WCAG, ${ }^{131}$ as well as helping to "ensure that different impacts are brought to the surface in every case and subjected to input from affected communities." 132

Rather than choosing one type of testing over another, however, we recommend that parties seeking to evaluate the accessibility of online legal information pair automated testing with user testing. A number of benefits flow from doing so. First, user testing may cover some areas that automated testing cannot cover, such as, in the context of the WCAG criteria, verifying that alternative text is sufficient. Second, pairing automated with user testing also creates an opportunity for persons with disabilities to be involved in the testing process. Third, pairing automated with user testing may give additional information with respect to the severity of each issue. For example, while automated or purely WCAG-based testing methods may have identified issues with the search design of various web pages, user testing ensured that the severity of these issues was noted. Given that accessibility problems with search functionality for a case database would frustrate attempts to use that functionality in a real-world situation, it is valuable that user testing highlights these issues. Fourth, pairing automated with user testing allows for the collection of more and different types of data, which can help to give a more complete picture of the website's accessibility. In the context of this study, for instance, pairing automated with user testing allowed us to collect both a wide set of automated testing results that spanned many web pages on each site, as well as a narrower but deeper set of user testing results which provided us with detailed feedback on accessibility issues on a number of individual pages. people's contexts and their means of interacting with the web beyond technical standards conformance"). 


\section{NEED FOR FURTHER TESTING}

\section{OTHER LEGAL MATERIALs DELIVERED \\ VIA THE INTERNET SHOULD BE TESTED}

This study focused on the accessibility of Canadian court websites. Given the wide range of legal information available online, however, further accessibility testing of different legal materials should be undertaken. This testing could be undertaken independently or internally (that is, by the content providers themselves). We wish to highlight two specific types of legal resources, in particular, that in our view merit further study: self-help resources aimed at the public, and practitioner-oriented content such as judgment databases and internal firm document management tools.

\section{i. $\quad$ Self-Help Legal Resources Aimed at the General Public}

Ensuring the accessibility of legal information aimed at the general public is important for many of the same reasons that ensuring accessibility of court websites is important, including to avoid perpetuating exclusion. ${ }^{133}$ One example of an institution that could benefit from accessibility testing using methodologies similar to the ones used in this study is the British Columbia Civil Resolution Tribunal, an online tribunal which handles strata and small claims actions and is geared towards non-lawyers. ${ }^{134}$ Smartphone apps that provide legal information could similarly benefit from accessibility testing. ${ }^{135}$

\section{ii. Legal Resources Primarily Used by Practitioners}

Services such as Westlaw and LexisNexis which are primarily used by practitioners and law students could also benefit from accessibility testing using similar methodologies to those employed in this study. In addition, further research on the accessibility of law firms' internal databases (such as document management systems) would be a valuable addition to the literature in this area.

\section{FurTher TeSting SHOUld INVESTIGATE ACCESSIBILITY ISSUES FACED BY MEMBERS OF OTHER VULNERABLE AND MARGINALIZED GROUPS}

This study identified accessibility issues encountered by users of Canadian court websites who are blind or who have visual impairments. However, different accessibility issues may be faced by members of other vulnerable and marginalized groups. We recommend further research in order to determine the extent to which online legal information is accessible both for users with disabilities other than visual impairments and, more generally, for users who

See Hughes, "Generic Solutions," supra note 7.

"Civil Resolution Tribunal: Home," online: $<$ https://civilresolutionbc.ca>. Accessibility testing is particularly important where inadequately accessible content could affect the outcome of a legal proceeding. 
are members of vulnerable or marginalized groups. ${ }^{136}$ The methodologies used in this study may prove useful in constructing these studies. The purpose of WCAG, for instance, is to address accessibility concerns associated with a range of disabilities, "including blindness and low vision, deafness and hearing loss, learning disabilities, cognitive limitations, limited movement, speech disabilities, photosensitivity and combinations of these."137

\section{Conclusion}

Technological developments have led to a significant amount of legal information being made available online, resulting in a number of access to justice benefits, including expanded access to lawyers and courts and further demystification of law. ${ }^{138}$ However, as is the case with any attempt to use technology to achieve positive access to justice outcomes, it is not necessarily the case that everyone benefits equally from steps taken to make legal information available online.

This article has considered the extent to which specific Canadian court websites and CanLII are accessible for persons who are blind or who have visual impairments. Our study found that the Canadian court websites that we tested are largely accessible for persons who are blind or who have visual impairments, but fall short of best practices in a number of ways. In order to ensure that online legal information is accessible for users who are blind or who have visual impairments, we recommended that Canadian courts take steps to correct some of the deficiencies identified in this study. As well, we recommended further testing (both automated and user) in order to pinpoint other accessibility issues that need to be resolved with respect to the provision of legal information online. To echo a recommendation from one of the co-authors, these may be best addressed through a nationwide discussion (potentially one "led or facilitated by the Canadian Judicial Council") and adoption of best practice guidelines. ${ }^{139}$

More broadly, our study suggests that it is critical to keep accessibility principles in mind to avoid excluding persons with disabilities from access to justice benefits provided by technology. While the relationship between technology and access to justice may be "neither necessary nor necessarily positive," 140 attention to the issues raised in this article and substantiated by our study could help to ensure more equal extension of the access to justice benefits that technology can provide.

For instance, further testing on the effectiveness of online delivery of legal information for persons affected by poverty, persons who have low literacy levels, persons of advanced age, or persons who live in rural areas would be welcome additions to the access to justice literature.

W3C, "WCAG 2.0," supra note 9.

See Macdonald, supra note 10.

Reynolds, supra note 31 at 111.

Bailey, Burkell \& Reynolds, supra note 11 at 183. 


\section{APPENDiX I:}

TABLES $^{141}$

TABLE 1:

VIOLATIONS OF FAE RULES BY WCAG GUIDELINE

\begin{tabular}{|l|l|l|l|l|l|l|l|}
\hline & $\begin{array}{l}\text { BCSC } \\
\text { BCCA }\end{array}$ & BCPC & CanLII & FC & FCA & $\begin{array}{l}\text { Ont Ct J } \\
\text { Ont Sup Ct J } \\
\text { Ont CA }\end{array}$ & SCC \\
\hline 1.1 Text Alternatives & 1 & 1 & & & & 1 & \\
\hline 1.2 Time-based Media & & & & & & & \\
\hline 1.3 Adaptable & & 4 & 4 & 1 & 2 & 3 & 10 \\
\hline 1.4 Distinguishable & & 1 & 1 & 1 & 1 & & \\
\hline 2.1 Keyboard Accessible & & & & & & & 1 \\
\hline 2.2 Enough Time & & & & & & & \\
\hline 2.3 Seizures & & & & & & & 2 \\
\hline 2.4 Navigable & 1 & 2 & 3 & & & 2 & \\
\hline 3.1 Readable & 1 & 1 & 1 & & & 1 & \\
\hline 3.2 Predictable & 3 & & & & & 2 & \\
\hline 3.3 Input Assistance & 5 & 2 & 1 & 1 & 1 & 2 & \\
\hline 4.1 Compatible & 1 & 1 & & & & 1 & \\
\hline
\end{tabular}

TABLE 2:

AVERAge SCORE by Site (ThOMPSON Five-Point SCALE)

\begin{tabular}{|l|l|}
\hline Average & $\mathbf{3 . 3 5 9}$ \\
\hline CanLII & 2.778 \\
\hline Ont CA & 3.042 \\
\hline Ont Ct J & 3.292 \\
\hline Ont Sup Ct J & 3.333 \\
\hline BCSC & 3.333 \\
\hline BCPC & 3.417 \\
\hline FCA & 3.458 \\
\hline SCC & 3.500 \\
\hline BCCA & 3.625 \\
\hline FC & 3.813 \\
\hline
\end{tabular}

141 These tables can also be found in an accessible format online: “Access to Justice Online: Supplement," supra note 91 . 
TABLE 3:

LOW USER FEEDBACK SCORES (THOMPSON FIVE-POINT SCALE)

\begin{tabular}{|l|l|l|l|}
\hline Website & 0 scores & 1 scores & 2 scores \\
\hline BCCA & & & 1 \\
\hline BCPC & & & 2 \\
\hline BCSC & & & 3 \\
\hline CanLII & 1 & 2 & 4 \\
\hline FC & & & \\
\hline FCA & & & 1 \\
\hline Ont CA & 2 & 1 & 1 \\
\hline Ont Ct J & & & 3 \\
\hline Ont Sup Ct J & & & 4 \\
\hline SCC & 1 & & 3 \\
\hline
\end{tabular}

TABLE 4:

Average Score by Page (Thompson Five-Point Scale)

\begin{tabular}{|l|l|}
\hline Page & $\begin{array}{l}\text { Average } \\
\text { Score }\end{array}$ \\
\hline Homepage & 3.537 \\
\hline Contact & 3.620 \\
\hline Court Website Judgment Search & 3.296 \\
\hline CanLII Search Tasks & 2.833 \\
\hline
\end{tabular}


TABLE 5:

ISSUES ENCOUNTERED IN USER TESTING - BY SITE

\begin{tabular}{|c|c|c|c|c|c|c|c|c|c|c|c|}
\hline Website & BCCA & ВCPC & BCSC & CanLII & FC & FCA & Ont CA & $\begin{array}{l}\text { Ont } \\
\text { Ct J }\end{array}$ & $\begin{array}{l}\text { Ont Sup } \\
\text { Ct J }\end{array}$ & SCC & Total \\
\hline No problems & 6 & 8 & 5 & 5 & 12 & 9 & 7 & 4 & 4 & 16 & 76 \\
\hline $\begin{array}{l}\text { Search design } \\
\text { problems }\end{array}$ & & 4 & & 8 & 2 & & 1 & 5 & 3 & 2 & 25 \\
\hline $\begin{array}{l}\text { "Skip to } \\
\text { content" or "to } \\
\text { top" link } \\
\text { missing/broken }\end{array}$ & 5 & 4 & 4 & & & 2 & 2 & 5 & 2 & & 24 \\
\hline $\begin{array}{l}\text { Insufficient } \\
\text { labels }\end{array}$ & & 3 & 2 & 2 & 2 & 1 & 2 & 5 & 5 & 2 & 24 \\
\hline Poor contrast & 4 & 3 & 4 & 1 & & & 3 & 3 & 3 & & 21 \\
\hline $\begin{array}{l}\text { Insufficient } \\
\text { alternative text }\end{array}$ & 3 & 4 & 4 & & 1 & 1 & 1 & 1 & 4 & 1 & 20 \\
\hline Structural issues & 1 & & 2 & & 1 & 3 & 1 & 1 & & 2 & 11 \\
\hline $\begin{array}{l}\text { Video plugin } \\
\text { issues } \\
\end{array}$ & & & & & & & & & & 7 & 7 \\
\hline Same link text & 1 & & 2 & & & & & & & 1 & 4 \\
\hline Unknown issues & & & & 1 & & & 1 & & & & 2 \\
\hline $\begin{array}{l}\text { Lack of subject } \\
\text { area knowledge }\end{array}$ & & & & 2 & & & & & & & 2 \\
\hline Pop-ups & & 1 & 1 & & & & & & & & 2 \\
\hline $\begin{array}{l}\text { Unpredictable } \\
\text { behaviour }\end{array}$ & & 1 & & & & & 1 & & & & 2 \\
\hline $\begin{array}{l}\text { Total issue- } \\
\text { related } \\
\text { comments }\end{array}$ & 14 & 20 & 19 & 14 & 6 & 7 & 12 & 20 & 17 & 15 & 144 \\
\hline
\end{tabular}


APPENDIX II:

USER TESTING SAMPLE SURVEY

Thank you for taking the time to complete this survey. If you are unable to find the requested information or function please write "not found". Please note if you receive any error messages or encounter any broken links throughout the website testing.

\section{Website Accessibility - [Court] Website}

\section{Accessibility of the [Court] website}

Please read and navigate the entire homepage.

Link to homepage: [URL]

How would you rank the accessibility of the homepage of the [Court] website?

$\square 4$ = accessible (alternate text for all graphics, skip to main content link if needed, appropriate tags on forms and tables, navigate/read page with ease)

$\square 3$ = mostly accessible (some improvements are needed)

$\square 2$ = fair (obvious accessibility problems exist but skilled users can perform functions with patience)

$\square 1=$ mostly inaccessible (accessible with difficulty)

$\square 0=$ inaccessible (cannot access the website)

$\square$ Other

Please explain your answer:

\section{Accessibility of the contact page of the [Court] website}

Please find, read and navigate the entire contact page (accessible through the homepage).

Link to homepage: [URL]

Please describe your experience locating the contact page of the [Court] website: 


\section{How would you rank the accessibility of the contact page of the [Court] website?}

$\square 4$ = accessible (alternate text for all graphics, skip to main content link if needed, appropriate tags on forms and tables, navigate/read page with ease)

$\square 3$ = mostly accessible (some improvements are needed)

$\square 2$ = fair (obvious accessibility problems exist but skilled users can perform functions with patience)

$\square 1=$ mostly inaccessible (accessible with difficulty)

$\square 0=$ inaccessible (cannot access the website)

$\square$ Other

Please explain your answer:

\section{Please locate [Style of Cause, Neutral Citation].}

Please attempt to find this judgment through the [Court] website (accessible through homepage).

Link to homepage: [URL]

Please describe your experience locating this judgment:

\section{Please rank your experience with locating this particular judgment:}

$\square 4$ = accessible (alternate text for all graphics, skip to main content link if needed, appropriate tags on forms and tables, navigate/read page with ease)

$\square 3=$ mostly accessible (some improvements are needed)

$\square 2$ = fair (obvious accessibility problems exist but skilled users can perform functions with patience)

$\square 1=$ mostly inaccessible (accessible with difficulty)

$\square 0=$ inaccessible (cannot access the website)

$\square$ Other 


\section{Accessibility Overview - [Court]}

1. Are you able to alter the size of the font?

$\square$ Yes

$\square$ No

$\square \mathrm{N} / \mathrm{A}$

2. Are you able to alter the style of the font?

$\square$ Yes

$\square$ No

$\square \mathrm{N} / \mathrm{A}$

3. Is there any text or content on the website that is unreadable using your assistive technology? (JAWS, Screen Reader, etc). If yes, describe your experience:

Do you think the accessibility of this website could be improved? If yes, how so?

How would you rank the accessibility of this website in general?

$\square 4$ = accessible

$\square 3=$ mostly accessible

$\square 2$ = fair

$\square 1=$ mostly inaccessible

$\square 0=$ inaccessible

$\square$ Other

Do you think the accessibility of this website could be improved for those using the same assistive technology? If yes, please explain: 
[this page is intentionally blank] 